\title{
Estenose ureteral após cistectomia radical associada à ureterostomia cutânea abdominal: relato de caso
}

[Ureteral stricture after radical cystectomy and cutaneous abdominal ureterostomy: case report]

\author{
G.R. Ledur, C. Gomes, C.A.C. Beck, L. Sonne, F.P.S. Mello, D.G. Gerardi
}

Universidade Federal do Rio Grande do Sul - Porto Alegre, RS

\begin{abstract}
RESUMO
O presente trabalho tem como objetivo relatar a realização de cistectomia total associada à ureterostomia abdominal, uma técnica ainda pouco descrita na veterinária, bem como descrever as complicações pósoperatórias observadas. Um canino da raça Akita, macho, 11 anos, castrado, foi atendido com histórico de prostração, hiporexia, disúria, hematúria e incontinência urinária havia aproximadamente 10 dias. No exame clínico, foi observada leve algia abdominal; demais parâmetros estavam dentro da normalidade. Os exames complementares de imagem revelaram presença de massa envolvendo grande parte da vesícula urinária. $\mathrm{O}$ paciente foi submetido à cirurgia de cistectomia total associada à implantação cutânea abdominal dos ureteres, e o exame histopatológico chegou ao diagnóstico de carcinoma de células de transicionais (CCT) infiltrativo não papilar. No pós-operatório, o paciente desenvolveu dermatite urêmica leve no local de inserção dos ureteres e estenose ureteral em região distal, de maneira que reintervenções cirúrgicas foram necessárias para a correção. Além disso, observaram-se pielonefrite e hidronefrose secundárias ao quadro obstrutivo. Devido às complicações pós-operatórias, a tutora optou pela eutanásia do cão. Dessa maneira, conclui-se que a estenose ureteral e a pielonefrite são possíveis complicações da técnica de cistectomia associada à implantação abdominal dos ureteres.
\end{abstract}

Palavras-chave: bexiga urinária, ureter, neoplasia, cirurgia

\begin{abstract}
This study aims to report the technique of total cystectomy associated with abdominal ureterostomy, a technique -little described in veterinary medicine, as well as to describe the postoperative complications observed. A male Akita canine, 11 years old, castrated, was attended with a history of prostration, hyporexia, dysuria, hematuria, and urinary incontinence for approximately ten days. The clinical examination revealed mild abdominal pain and other parameters within the normal range. Complementary imaging studies revealed the presence of mass involving a large part of the urinary bladder. The patient underwent total cystectomy surgery associated with abdominal cutaneous implantation of the ureters and histopathological examination led to a diagnosis of non-papillary infiltrative transitional cell carcinoma. In the postoperative period, the patient developed mild uremic dermatitis at the insertion site of the ureters and ureteral stenosis in the distal region, so that surgical reinterventions were necessary for correction. In addition, pyelonephritis and hydronephrosis secondary to the obstructive condition were observed. Due to the postoperative complications, the tutor chose to euthanize the dog. Thus, it is concluded that ureteral stenosis and pyelonephritis are possible complications of the cystectomy technique associated with abdominal implantation of the ureters.
\end{abstract}

Keywords: urinary bladder, ureter, neoplasm, surgery

\section{INTRODUÇÃO}

Os tumores vesicais são considerados incomuns em cães e correspondem a aproximadamente $2 \%$ de todos os tumores malignos relatados nessa espécie (Mutsaers et al., 2003; Chew et al., 2011;

Recebido em 18 de maio de 2017

Aceito em 1 de fevereiro de 2018

E-mail: gabirledur@hotmail.com
Knapp e McMillan, 2013). Entre os diferentes tipos neoplásicos que podem acometer a vesícula urinária, o carcinoma de células transicionais é o tipo mais comum (Knapp e McMillan, 2013).

A etiologia dos CCT é considerada multifatorial e, aparentemente, existe uma predisposição 
racial. Sugere-se também uma predisposição sexual, com fêmeas entre nove e 11 anos sendo as mais acometidas (Henry et al., 2003; Mutsaers et al., 2003).

Os sinais clínicos são associados a doenças do trato urinário e compreendem alterações tais como: polaquiúria, hematúria, estrangúria ou tenesmo. De maneira menos comum, sinais de claudicação, letargia e perda de peso também podem ocorrer (Mutsaers et al., 2003).

O tratamento cirúrgico é, geralmente, paliativo, devido ao envolvimento do trígono vesical e da uretra e ao caráter infiltrativo e metastático da neoplasia (Rossetto et al., 2009). Ao contrário da intervenção realizada em humanos, a cistectomia total como opção terapêutica é pouco descrita em animais, pois apresenta a desvantagem da ocorrência de incontinência urinária (Mutsaers et al., 2003; Boston e Singh, 2014). O presente trabalho tem como objetivo relatar a realização de cistectomia total associada à ureterostomia abdominal e suas complicações pós-operatórias em cão da raça Akita com carcinoma de células transicionais infiltrativo.

\section{CASUÍSTICA}

Foi atendido um cão, da raça Akita, castrado, com 11 anos de idade, apresentando histórico de prostração, hiporexia, disúria, hematúria e incontinência urinária havia aproximadamente 10 dias. $\mathrm{O}$ paciente havia passado por avaliação em clínica particular e havia sido medicado com sulfadiazina e trimetoprim (15mg/kg/BID) e dipirona gotas $(25 \mathrm{mg} / \mathrm{kg} / \mathrm{TID})$ por sete dias. Segundo relato da tutora, com o tratamento realizado o paciente mostrou-se discretamente mais ativo, contudo o quadro de disúria, hematúria e incontinência permaneceu inalterado.

Ao exame clínico, o cão estava alerta e mostrou desconforto abdominal leve. Demais parâmetros clínicos avaliados estavam dentro dos padrões de normalidade e a inspeção da região peniana não evidenciou nenhuma alteração macroscópica. Como exames complementares, foram solicitados: ultrassonografia abdominal, radiografia torácica (três projeções), hemograma completo, alanina aminotransferase, albumina, creatinina, urinálise, cultura e citologia da urina. O ultrassom (US) mostrou presença de estrutura ecogênica, com bordas irregulares, medindo cerca de 2,57 x $5,13 \mathrm{~cm}$, bastante vascularizada ao estudo Doppler, com origem aparentemente na parede vesical. A avaliação dos rins direito e esquerdo mostrou simetria bilateral, dimensões preservadas, contornos regulares, arquitetura e ecogenicidade preservadas. Foi observada diminuição da definição da relação corticomedular renal, sugestiva de senilidade ou nefropatia. Os ureteres não foram visualizados no exame, sugerindo diâmetro normal. O estudo radiográfico do tórax, o hemograma completo e a bioquímica sérica apresentavam-se dentro dos padrões de normalidade. Na urinálise, observouse urina de coloração amarronzada, aspecto turvo, densidade de 1026, acentuada presença de sangue oculto, presença de células escamosas (03 células/campo 400x), células de transição (2-5 células/campo 400x), leucócitos (5-20/campo 400x), ausência de bactérias, muco e espermatozoides. A análise citológica do sedimento detectou elevada celularidade e células com aspecto displásico, sugerindo-se afecção neoplásica (carcinoma de células transicionais).

Após resultados dos exames, foi indicada a ressecção cirúrgica da massa e tratamento de suporte com carprofeno $(4,4 \mathrm{mg} / \mathrm{kg} / \mathrm{SID})$, amoxicilina com ácido clavulânico (20mg/kg/BID) e omeprazol (1mg/kg/SID). Por motivos pessoais, a tutora não pôde realizar o procedimento cirúrgico na data combinada, sendo necessária reavaliação após 26 dias da data da primeira consulta. $\mathrm{Na}$ reavaliação, a tutora relatou que não houve resposta à terapia clínica proposta e que o paciente apresentava dor abdominal evidente, hematúria intensa, urina com odor forte e apetite seletivo. Novo ultrassom abdominal foi solicitado e observou-se aumento evidente da massa vesical (medição de aproximadamente $6,5 \mathrm{~cm}$ de diâmetro). A avaliação dos rins e o diâmetro dos ureteres, não apresentavam alteração em relação ao exame ultrassonográfico anterior.

Dois dias após a reconsulta, foi realizada cistectomia total associada à ureterostomia abdominal, e a massa vesical foi encaminhada para análise histológica. Para a realização do procedimento cirúrgico, a cavidade abdominal foi acessada pela linha média ventral, a bexiga foi isolada e removida por completo. O ligamento dos vasos sanguíneos foi realizado com poliglactina 910 (número 3-0). O fechamento da uretra foi feito com sutura do tipo 
Cushing, também com poliglactina 910 (número 4-0). Os ureteres foram tracionados e implantados em região abdominal ventral aproximadamente $1 \mathrm{~cm}$ lateral às mamas abdominais caudais (Fig. 1A). Para implantação dos ureteres à pele, as porções distais foram espatuladas com uma incisão longitudinal de $0,5 \mathrm{~cm}$ e fixadas à porção ventrolateral do abdômen com pontos interrompidos simples realizados com fio de náilon 4-0. Para a fixação dos ureteres à pele, teve-se o cuidado em promover uma eversão da mucosa do ureter, e sondas ureterais (número 8) foram fixadas bilateralmente.

No pós-operatório imediato, foi administrado cloridrato de tramadol $(4 \mathrm{mg} / \mathrm{kg})$, meloxican $(0,2 \mathrm{mg} / \mathrm{kg})$, dipirona $(25 \mathrm{mg} / \mathrm{kg})$ e ampicilina $(22 \mathrm{mg} / \mathrm{kg})$. A conclusão do exame histológico foi carcinoma de células transicionais não papilar infiltrativo (Fig. 1C). O paciente ficou internado para acompanhamento da cicatrização e foi medicado com amoxicilina com ácido clavulânico (20mg/kg/BID), ranitidina (2mg/kg/BID), meloxican $(0,1 \mathrm{mg} / \mathrm{kg} / \mathrm{SID})$ tramadol $(3 \mathrm{mg} / \mathrm{kg} / \mathrm{TID}) \quad$ e dipirona (25mg/kg/TID), além de limpeza dos locais de inserção dos ureteres com clorexidina $0,12 \%$ e troca de fralda duas vezes por turno. Apesar das trocas frequentes das fraldas, $\mathrm{o}$ paciente desenvolveu dermatite urêmica na região de inserção dos ureteres e foi tratado com pomadas à base de óxido de zinco (Hipoglós®, óxido de zinco, retinol, colecalciferol e óleo de fígado de bacalhau; Jonhson \& Jonhson, Brasil).

Durante o período de internação, mesmo apresentando bom estado geral, foram solicitados exames de check up. O hemograma revelou anemia normocítica hipocrômica (hematócrito $24 \%$ - referência 37 a 55\%). Demais parâmetros hematológicos e bioquímicos apresentaram-se dentro dos padrões de normalidade. A urinálise mostrou urina com aspecto límpido, coloração amarelo-clara, densidade de 1014, pH 6, ausência de sangue oculto, leucócitos, espermatozoide, muco e bactérias. No oitavo dia, foram removidas as sondas ureterais e, um dia após sua remoção, foi observado que, no local de inserção do ureter esquerdo, não havia gotejamento de urina. Um novo procedimento de sondagem foi realizado, contudo, no ureter esquerdo, a sonda não progredia completamente e não havia refluxo de urina. Por este motivo, foi solicitada ultrassonografia abdominal controle, que mostrou dilatação do ureter esquerdo e hidronefrose. Para confirmação da suspeita de obstrução do ureter, realizou-se urografia excretora, por meio da qual foi observado retardamento na excreção renal esquerda, dilatação da pelve bilateral, dilatação proximal de ureter bilateral de aproximadamente $2 \mathrm{~cm}$ de diâmetro por $4 \mathrm{~cm}$ de extensão e forte sinuosidade em região proximal do ureter esquerdo, com evidência de prosseguimento do contraste para a região proximal à musculatura abdominal, sugerindo-se obstrução distal (Fig. 1B). No mesmo dia, foi recomendada reintervenção cirúrgica, e novos exames hematológicos e bioquímicos foram solicitados.

O hemograma mostrou anemia normocítica hipocrômica (hematócrito 23\%), contagem de reticulócitos 4,2\%, creatinina $1,58 \mathrm{mg} / \mathrm{dL}$ (referência 0,5 - 1,5mg/dL). Quatro dias após identificação da obstrução, o paciente passou por procedimento videolaparoscópico para correção da obstrução distal do ureter esquerdo. Nessa ocasião, o pós-operatório foi realizado em ambiente domiciliar. Em revisão, após 13 dias do procedimento laparoscópico, observou-se obstrução total do ureter direito. Novo procedimento cirúrgico foi realizado no mesmo dia, pois o exame ultrassonográfico controle evidenciou dilatação do ureter de, aproximadamente, $2,5 \mathrm{~cm}$ de diâmetro (Fig. 1D), sinais evidentes de hidronefrose com destruição do parênquima renal e acúmulo de líquido subcapsular. No sétimo dia de pós-operatório, foi observado que o ponto de inserção do ureter esquerdo estava gravemente estenosado (Fig. 1A), o paciente estava apático e, segundo relato da tutora, não se alimentava havia três dias. Novos exames hematológicos e bioquímicos foram solicitados e observou-se hematócrito de $31 \%$, leucocitose $(25000 \mu \mathrm{L}$; referência 6000 $17000 \mu \mathrm{L})$ por neutrofilia $(20000 \mu \mathrm{L}$; referência 3000 - $11500 \mu \mathrm{L})$ e monocitose $(2500 \mu \mathrm{L}$; referência 150 - $1350 \mu \mathrm{L})$, elevação da creatinina $(4,18 \mathrm{mg} / \mathrm{dL}$; referência $0,5-1,5 \mathrm{mg} / \mathrm{dL})$, da ureia $(142 \mathrm{mg} / \mathrm{dL}$; referência $21-60 \mathrm{mg} / \mathrm{dL})$ e do fósforo $(7,4 \mathrm{mg} / \mathrm{dL}$; referência $2,6-6,2 \mathrm{mg} / \mathrm{dL})$. A cultura da urina evidenciou crescimento da bactéria Escherichia coli. Após resultados dos exames, a tutora optou pela eutanásia do paciente, contudo não autorizou exame de necropsia. 


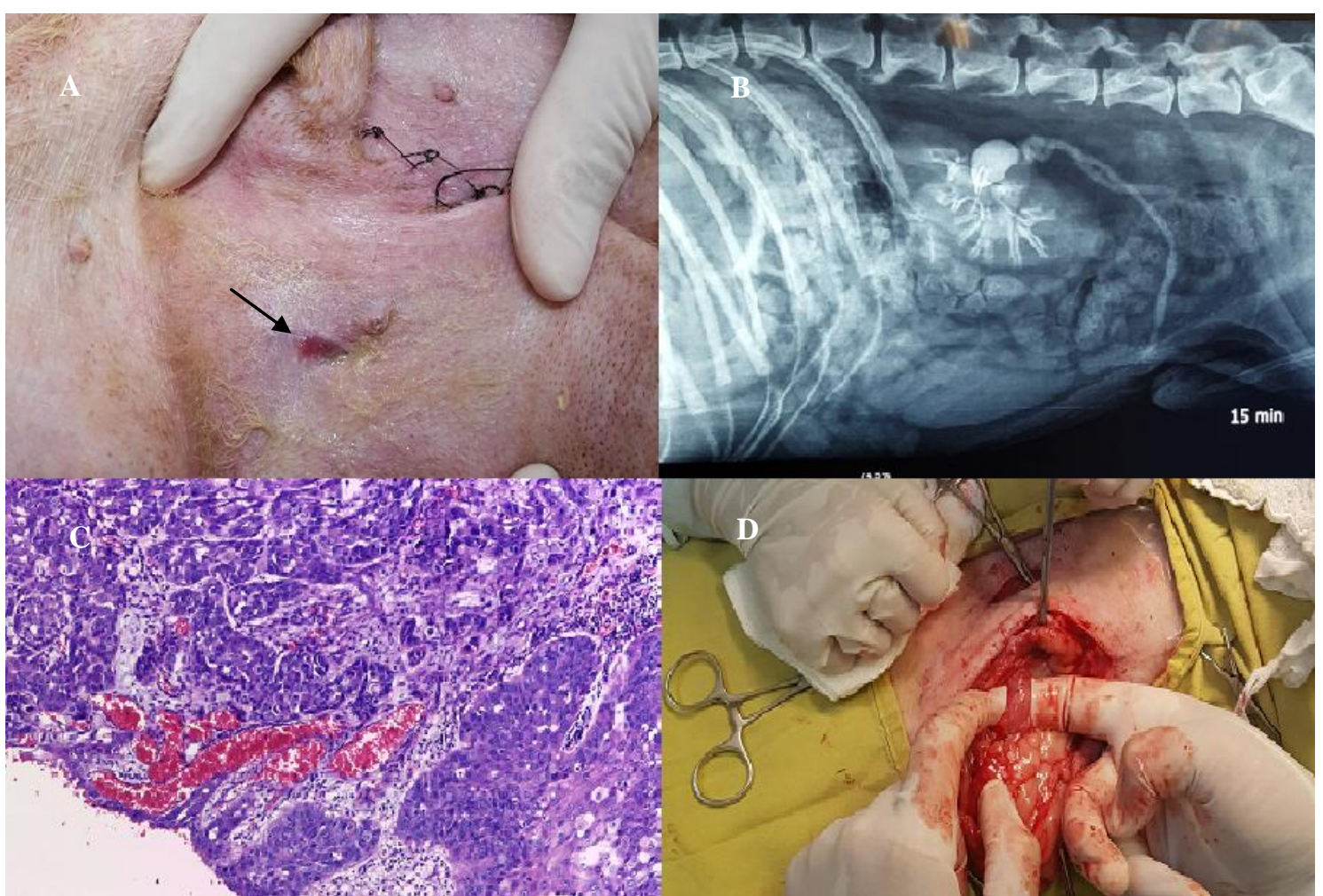

Figura 1. (A) Localização anatômica do orifício ureteral e complicação pós-operatória de procedimento de cistectomia total associada à implantação dos ureteres na parede abdominal devido à ocorrência de carcinoma de células transicionais. Observa-se obstrução total no local de inserção do ureter direito (seta) e dermatite urêmica leve na periferia. (B) Projeção radiográfica laterolateral direita após 15 minutos da administração do contraste para realização de urografia excretora. Observa-se forte sinuosidade em região proximal do ureter esquerdo, com evidência do prosseguimento do contraste que para em região proximal musculatura abdominal, sugerindo obstrução de ureter distal. (C) Proliferação neoplásica de células transicionais infiltrativa e não papilar com infiltrado inflamatório de linfócitos. HE, 10x. (D) Dilatação ureteral (hidroureter) secundária a obstrução pós-renal, visualizada durante procedimento cirúrgico realizado para correção da obstrução do ureter.

\section{DISCUSSÃO}

O desvio urinário, quando consiste de uma cistotomia total e do transplante ureteral, pode ser considerado uma opção terapêutica quando o trígono vesical está acometido (Knapp e McMillan, 2013), conforme ocorrido no cão do presente relato. Todavia, a remoção completa da vesícula urinária é uma opção terapêutica incomum em cães devido às diversas complicações associadas à implantação dos ureteres (Boston e Singh, 2014). Stone et al. (1988) descreveram uma técnica de cistectomia total associada à anastomose ureterocolônica. Tal técnica, apesar da vantagem em manter a continência urinária devido ao esfíncter anal, está associada a complicações graves, tais como hiperamonemia, pielonefrite, hidroureteronefrose, entre outras, que acabam por reduzir sua utilização (Stone et al., 1988; Boston e Singh, 2014). No presente relato, com o intuito de evitar complicações decorrentes da técnica de anastomose ureterocolônica, optou-se por uma técnica alternativa de implantação dos ureteres na parede abdominal, conforme descrito por Huppes et al. (2016).

A maior desvantagem da técnica de cistectomia total está relacionada à incontinência urinária, ao potencial de infecção ascendente e à estenose da uretra ou ureteres (Boston e Singh, 2014). No presente relato, a incontinência urinária, que ocorreu devido à técnica empregada (Huppes et al., 2016), foi manejada com o uso de fraldas de maneira satisfatória. Contudo, apesar da constante troca de fraldas (cada quatro ou seis 
horas), o paciente desenvolveu leve dermatite urêmica, que foi tratada com o uso de pomadas à base de óxido de zinco e fígado de bacalhau (Hipoglós®) e não foi considerada pela tutora como fonte de desconforto. Da mesma forma, Huppes et al. (2016) descrevem a dermatite urêmica como uma complicação e relatam que o manejo com pomadas à base de óxido de zinco também se mostrou efetivo, não afetando a qualidade de vida dos pacientes. A aceitação da incontinência urinária e do uso da fralda é bastante variável entre os tutores (Boston e Singh, 2014), contudo o cão do presente relato estava incontinente antes do procedimento cirúrgico e, por esse motivo, acredita-se que a incontinência urinária pós-operatória não tenha sido considerada um fator impeditivo por parte da tutora.

A estenose da uretra ou ureter proximal é uma complicação possível da técnica (Troff et al., 2008; Huppes et al., 2016), conforme observado no presente relato. $\mathrm{Na}$ série de casos descritos por Huppes et al. (2016), a estenose ureteral não foi observada como uma complicação pósoperatória. Contudo, conforme o próprio autor, a seleção de casos com hidroureter documentados pode ter contribuído para reduzir tal complicação, uma vez que, devido à dilatação do lúmen ureteral, a sutura na pele torna-se mais fácil, bem como reduz a chance de obstrução. Como tentativa de evitar a obstrução ureteral, optou-se por espatular a extremidade distal dos ureteres como forma de ampliar seu diâmetro (Huppes et al., 2016). No entanto, no presente relato, a incisão espatulada e a fixação ventrolateral do ureter à pele, a fim de manter sempre a eversão da mucosa, não foram suficientes para evitar a estenose do orifício ureteral. Dessa forma, supõe-se que os diâmetros iniciais dos ureteres influenciaram, de maneira negativa, os resultados, pois admite-se que a não ocorrência de hidroureter no paciente pode ter contribuído para a estenose do ureter na sua porção distal e, apesar do desenvolvimento de tal alteração (hidroureter) nos procedimentos corretivos posteriores, a formação de tecido de granulação exuberante levou ao insucesso neste caso.

O local de implantação dos ureteres foi escolhido conforme a descrição da técnica cirúrgica utilizada (Huppes et al., 2016). Por esse motivo, acredita-se que a localização não influenciou nos resultados obtidos, uma vez que o local estava livre de tecido adjacente que pudesse dificultar a drenagem de urina, bem como não apresentava nenhuma fonte de contaminação próxima aos orifícios de drenagem, além de as suturas não apresentarem tensão e estarem evertidas. Uma possibilidade que deve ser considerada na avaliação final dos quadros obstrutivos sucessivos refere-se a uma possível reação da parede abdominal à técnica do estoma associada à presença do fio de sutura. Apesar de o fio de náilon utilizado para a fixação do ureter à pele ser pouco reativo, sugere-se que a reação inflamatória exuberante possa ter relação com alguma sensibilidade aumentada do paciente à presença do fio que, por sua vez, levou à obstrução ureteral. Tal hipótese é sugerida devido às rápidas e sucessivas estenoses observadas poucos dias após a retirada das sondas ureterais.

Atualmente, uma forma mais adequada de se manejar a obstrução ureteral foi descrita por Weisse et al. (2006) com a utilização de stents. Nesse trabalho, foi descrita a utilização de stents ureterais em 12 cães, com excelentes resultados observados em sete casos. No presente relato, apesar da utilização de sonda ureteral de maneira mais prolongada (oito dias), acredita-se que a manutenção de stent permanente poderia ter contribuído para evitar a estenose dos ureteres e sugere-se que, em casos futuros, tal possibilidade seja considerada de maneira prévia.

A pielonefrite por Escherichia coli, diagnosticada pela cultura de urina, também não foi uma complicação descrita por Huppes et al. (2016). Todavia, Saeki et al. (2015) descreveram uma série de 10 casos, nos quais foi realizada cistectomia total com desvio dos ureteres para o prepúcio ou para a vagina, e a pielonefrite foi uma complicação observada em três cães. Nesse mesmo estudo, nos três cães acometidos por pielonefrite, não foi observado nenhum fator complicador (hidronefrose, hidroureter ou sinal de obstrução pós-renal) que pudesse ter contribuído para o quadro de infecção bacteriana. Tal observação diverge do sugerido para o presente relato, pois o paciente em questão desenvolveu dilatação do ureter e obstrução pósrenal, alterações que podem ter contribuído para o desenvolvimento da pielonefrite. Além disso, acredita-se que os três procedimentos cirúrgicos/anestésicos realizados em um curto 
intervalo de tempo também possam ter contribuído para um maior comprometimento do sistema imune do paciente e, consequentemente, favorecido a ocorrência da infecção renal ascendente. A azotemia observada no sétimo dia de pós-operatório pode ser decorrente da pielonefrite e da obstrução pós-renal, caracterizando um quadro de injúria renal póscirúrgica. Assim, as complicações sistêmicas (injúria renal e pielonefrite) associadas aos repetidos quadros de obstrução ureteral culminaram com a debilidade clínica do cão e levaram a tutora a optar pela eutanásia do paciente.

\section{CONCLUSÃO}

A cistectomia total associada à implantação dos ureteres na parede abdominal é uma técnica viável, porém deve-se considerar a possibilidade de ocorrência de estenose ureteral e pielonefrite como complicações pós-cirúrgicas.

\section{REFERÊNCIAS}

BOSTON, S.; SINGH, A. Total cystectomy for treatment of transitional cell carcinoma of the urethra and bladder trigone in a dog. Vet. Surg., v.43, p.294-300, 2014.

CHEW, D.J.; DiBARTOLA, S.P.; SCHENCK, P.A. Tumores do sistema urinário. In: (Eds.). Urologia e nefrologia do cão e do gato. Rio de Janeiro: Elsevier, 2011. p.434-464.

HENRY, C.J. Management of transitional cell carcinoma. Vet. Clin. Small. Anim., v.33, p.597613,2003
HUPPES, R.R.; CRIVELLENTI, L.Z.; DE NARDI, A.B. et al. Radical cystectomy and cutaneous ureterostomy in 4 dogs with trigonal transitional cell carcinoma: description of technique and case series. Vet. Surg., v.46, p.111-119, 2016.

KNAPP, D.K.; McMILLAN, S.K. Tumors of the urinary system. In: WITHROW, S.J.; VAIL, D.M.; PAGE, R.L. (Eds.). Small Animal Clinical Oncology. Sant Louis: Elsevier Health Sciences, 2013. p.572-582.

MUTSAERS, A.J.; WIDMER, W.R.; KNAPP D.W. Canine transitional cell carcinoma. J. Vet. Intern. Med., v.17, p.136-144, 2003.

ROSSETTO, V.J.V.; BRANDÃO, C.V.; RANZANI, J.J.T. et al. Exérese radical de carcinoma de células transicionais em bexiga de cão: tempo de sobrevida superior a dois anos. Vet. Zootec., v.16, p.321-324, 2009.

SAEKI, K.; FUGITA, A.; NAKAGAWA, T. et al. Total cystectomy and subsequente urinary diversion to the prepuce or vagina in dogs with transitional cell carcinoma in dogs. Can. Vet. J., v.56, p.73-80, 2015.

STONE, E.A.; WITHROW, A.J.; SCHWARZ, P.D. Ureterocolonic anastomosis in ten dogs with transitional cell carcinoma. Vet. Surg., v.17, p.147-153, 1988.

TROFF, F.G.S.; BUSONI, V.; HAMAIDE, A. A technique for ressection of invasive tumors involving the trigone area of the bladder in dogs: preliminar results in two dogs. Vet. Surg., v.37, p.427-437, 2008.

WEISSE, C.; BERENT, A.; TODD, K. et al. Evaluation of palliativ stenting for management of malignant urethral obstructions in dogs. J. Am. Vet. Med. Assoc., v.229, p.226-234, 2006. 